ORIGINAL ARTICLE

\title{
The effect of acute exercise on cognition
}

\author{
Blanka Dwojaczny ${ }^{1 \mathrm{BCD}}$, Sergii Iermakov ${ }^{2 \mathrm{ADE}}$, Tetiana Yermakova ${ }^{3 \mathrm{ADE}}$, Mirosława Cieślicka ${ }^{1 \mathrm{ADE}}$ \\ ${ }^{1}$ Collegium Medicum im. L.Rydygiera in Bydgoszcz, Nicolaus Copernicus University in Toruń, Poland \\ ${ }^{2}$ Gdansk University of Physical Education and Sport, Poland \\ ${ }^{3}$ Kharkiv State Academy of Design and Arts, Ukraine
}

Authors' Contribution: A- Study design; B- Data collection; C- Statistical analysis; D- Manuscript Preparation; E-Funds Collection

\begin{abstract}
Purpose: $\quad$ Several lines of evidence indicate that physical activity has a positive impact on central nervous system. The positive impact is observed in areas of brain related to cognitive processes such as memory, learning and attention. The majority of studies focused on the chronic effects of exercise. Relatively limited number of reports addresses the problem of influence of acute exercise (single bouts of exercise) on cognitive functions.

Material: $\quad$ We examined the influence of a single bout of exercise on cognitive performance of young volunteers (23 males; aged 20,91 $\pm 1,01$ ). To evaluate the cognitive performance in our subjects we used Face/Name Association Test, Stroop Test and Trail Making Test. Volunteers run for 30 minute at moderate -intensity.

Results: $\quad$ The mean results in the Face/Name Association Test before acute exercise were 63,52 $\pm 5,65 \%$ and after acute exercise $67,34 \pm 5,82 \%$ ( $p<0,005)$. Statistically differences results were also observed in duration of the retrieval phase of this test $(p<0,005)$. In the Trial Making Test, in part A mean results before acute exercise were $66,26 \pm 11,24$ seconds and after physical training $52,39 \pm 11,10$ seconds $(p<0,005)$. In part $B$ mean results were $80,60 \pm 22,52$ and $70,47 \pm 14,54$ seconds before and after acute exercise, respectively $(p<0,05)$. We have not observed statistical difference in results of the Stroop Test.

Conclusions: Our data suggest that a single bout of exercise can influence the level of cognitive performance. We demonstrate improvement in cognitive function depending on hippocampus (short-term memory) and prefrontal cortex (attention, cognitive flexibility). We have not observed influence of acute exercise on Stroop test (executive function) results.

Keywords: short-term memory, cognitive flexibility, hippocampus, prefrontal cortex, cognitive tests
\end{abstract}

\section{Introduction}

Regular physical activity exerts beneficial influences on several aspect of the central nervous system. In particular, the positive effects are observed in the areas of brain which are related to cognitive processes such as memory, learning and attention [1-4]. Currently it is accepted that regular physical activity leads to improvement of cognitive function via stimulation of neural stem cells proliferation, increases the survival of newly formed nerve cells [2, 3, 5]. Physical exercise enhances cognitive function in both young and older adults but in elderly humans' regular physical exercise additionally helps reduce the risk of neurodegenerative diseases [6-9].

Majority of research focused on the chronic effects of exercise [10-12]. Relatively limited number of research addresses the problem influence of acute exercise (single bouts of exercise) on cognition [13-16]. Previous research indicates that acute bout moderate aerobic exercise improves choice reaction task [17, 18], simple reaction task $[19,20]$ and confliction task [21].

Other studies reported the following:

- acute exercise improves only prefrontal cortex function such as attention, concentration, reasoning and planning but not hippocampal function [22-24];

- acute high-intensity exercise may enhance true

(c) Blanka Dwojaczny, Sergii lermakov, Tetiana Yermakova,

Mirosława Cieślicka, 2020

doi:10.15561/20755279.2020.0604 episodic memories, and possibly, also increase the rate of false episodic memories [25];

- acute moderate-intensity aerobic exercise is not associated with prospective memory performance but provides some suggestive evidence that acute exercise may reduce the rate of false memories [26];

- 20 minutes of moderate-intensity exercise benefits EF (executive function) performance in high school students [27];

- $\quad$ acute exercise demonstrates different time-dependent effects of acute exercise on cognition in TEMP and COLD. Study reveals facilitating effects of exercise on university students' processing speed and working memory in both environments. However, in contrast to TEMP, effects on working memory in COLD are transient [28].

There is still very limited research which showed that acute exercise improves long-term memory, associative memory and learning [15, 29-31].

The potential mechanism through a single bout of exercise can influence on cognitive function is unclear. The effect of acute exercise on cognition seems to be depend on many factors: type of exercise, intensity, duration, time course post-exercise cessation.

Therefore, it seems necessary to carry out further research which clearly indicate that impact of single bout of exercise on cognitive process. In the current study we determine the impact of 30 minutes of running on the 
cognitive function such as: declarative memory, selective attention, ability to inhibit habitual responses, attention and cognitive flexibility before and after acute physical activity.

\section{Material and Methods}

\section{Participants.}

The study was conducted in accordance with the Declaration of Helsinki for Human Studies. The study protocol was approved by a local Ethics Committee.

Volunteers (23 males; aged 20, 91 $\pm 1,01$ ) were recruited from the Kazimierz Wielki University in Bydgoszcz (Poland). The volunteers were students from the Faculty of Physical Education. In order to limit the influence of hormonal factors on the obtained results only boys were qualified in this study. In order to limit the differences in their level of education, physical activity and socioeconomic background, all volunteers were students of the same faculty. All students were regularly engaged in weakly schedule at least 9 hours of supervised intense physical activity (including soccer, competitive swimming, volleyball, track athletics).

\section{Research Design.}

Evaluation of cognitive abilities was based on scores obtained by participants in Face/Name Association Test, Stroop Test and Trial Making Test. All cognitive tasks were conducted both before and after acute exercise session. The detailed experimental protocols for these tests were described previously [32]. Shortly, in the acquisition phase of the face/name association test, subjects were exposed to 100 faces associated with a single name on a computer screen. Each face/name pair was presented for 2 seconds. After $10 \mathrm{~min}$ from the end of acquisition phase the retrieval phase began. During this phase test subjects were presented with the same faces as in acquisition phase but each face was associated with two names, one of which was the same name as in acquisition phase. The task of the subject was to indicate the name associated with the face during acquisition phase. No time limitations for retrieval phase were imposed by the protocol. The percent of correctly answered names, and the duration of the retrieval phase were monitored for each subject. Face/name test evaluating short-term declarative memory associated with hippocampal activity [33].

The Stroop test consisted of four pages. The first test page contained the names of colours written in two columns in black ink ( 20 words in each column). The task was to read the names of colours. The second page contained the rows of cross marks in two columns (20 rows in each column). The rows of cross marks were displayed in different colours. A colour of each row was recognized and pronounced by each participant. The third and fourth pages contained the names of colours written in two 20word columns. An ink colour was different than the name of a colour. The written name of colour (third page) or the colour of the ink (fourth page) were recognized and pronounced by each subject. For each page the time of reading duration was recorded. In the statistical analysis we used the reading time of the last page expressed as a percentage of the first page reading time. The Stroop test measure multiple cognitive processes such as executive control, selective attention and ability to inhibit habitual responses $[34,35]$. These abilities are strongly associated with the activity of prefrontal and anterior cingulate cortical areas [36].

The Trail Making Test consisted of two pages. The first page contained numbers from 1 to 25 which are randomly arranged on a piece of paper. The task of the subject is to connect numbers of a continuous line (without revealing a paper and pencil). The second page contained numbers (from 1 to 13) and letter (from A to L) which are randomly arranged on a paper. The task of the subject is to connect alternately numbers and letters (without revealing paper and pencil). The result of the test is the time it took to complete part A and part B, respectively. TMT test measures prefrontal cortex-dependent attention and cognitive flexibility [37].

Volunteers were engaged in 30 minutes running at moderate-intensity $(16 \mathrm{~km} / \mathrm{h})$. Physical activity session with 5-min.warn up and 5-min. cool down period for a total of $40 \mathrm{~min}$. of exercise. Cognitive tests took place 2030 minutes after physical training.

All tests were performed between 9:00 am and $14 \mathrm{pm}$.

Statistical Analysis.

Statistical significance of the differences between before-exercise tests and after-exercise tests was assessed using two-tailed paired T-Test. The results are presented as means with standard deviation. $\mathrm{p}<0.05$ was considered statistically significant.

\section{Results}

The mean score of Face/Name Association Test before acute exercise was $63,52 \pm 5,65 \%$, after the exercise the scores were $67,34 \pm 5,82 \% .19$ volunteers improved their score. The score decreased in 4 volunteers (Fig.1). In the same test before acute exercise the mean retrieval duration equalled 301, $21 \pm 78,97$ seconds, after acute exercise mean retrieval duration equalled $259,26 \pm 55$, 83 seconds. 19 volunteers improved their score. The score decreased in 4 volunteers (Fig. 2). Statistically significant differences were observed between percentage of correctly recognized pair face/name and the duration of the retrieval phase of this test.

We also observed statistically differences in a Trail Making Test $(\mathrm{p}<0.005)$. The mean results in TMT A before acute exercise were 66, $26 \pm 11,24$ seconds, after acute exercise the mean results were $52,39 \pm 11,10$ seconds. 20 volunteers improved their score. The score decreased in 3 volunteers (Fig. 3). The mean results in TMT B before acute exercise were $80,60 \pm 22,52$ seconds. After the acute exercise the mean results were $70,47 \pm 14,54$ seconds. 18 volunteers improved their score. The score remained unchanged in 1 and decreased in 4 volunteers (Fig.4). Statistically differences were observed between results before and after for TMT A $(p<0,005)$ and for TMT B $(\mathrm{p}<0,05)$.

Statistically differences were not observed in Stroop test conducted before and after acute exercise. The mean 


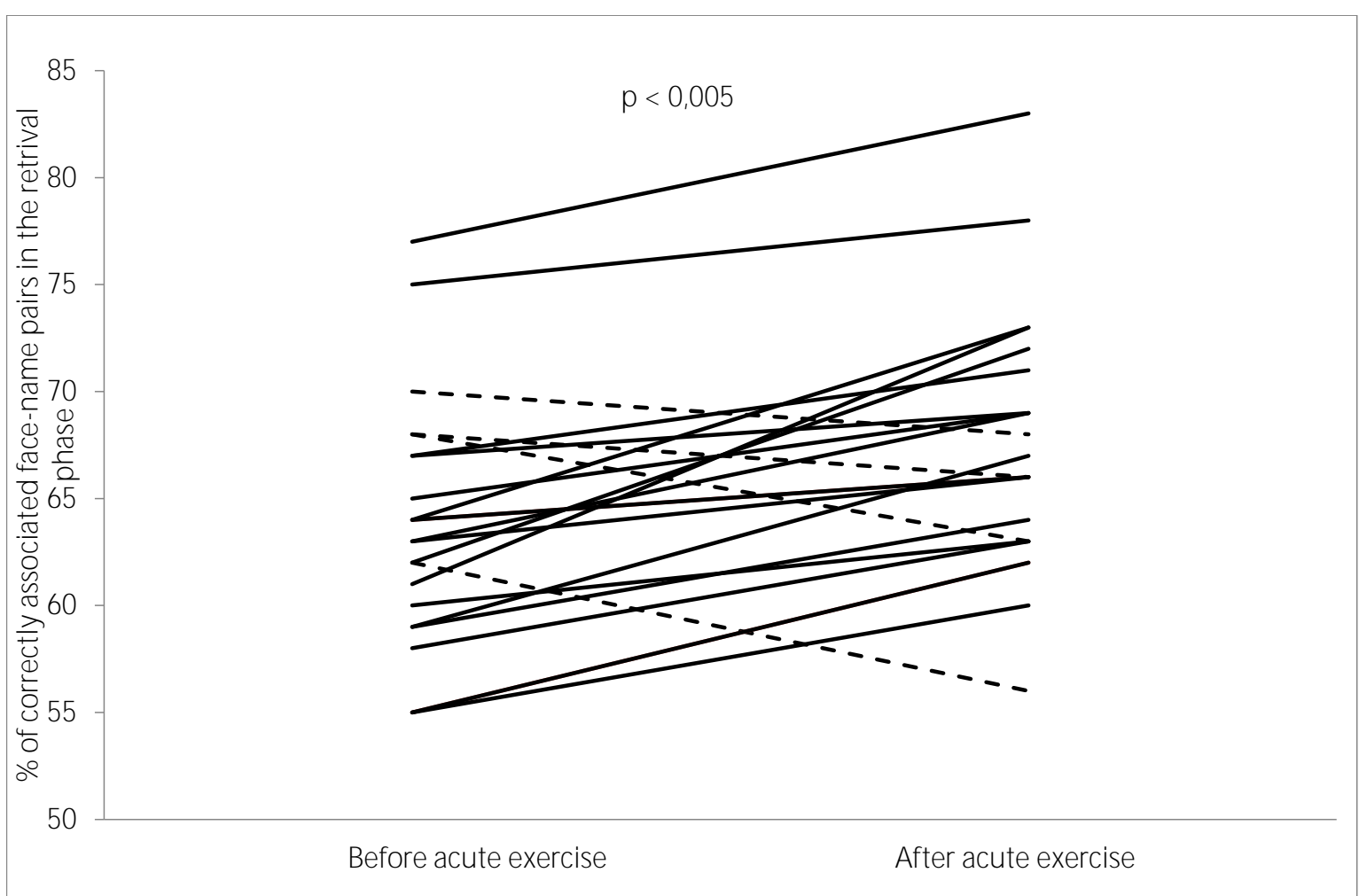

Fig.1. Individual scores in the face/name association test - \% correctly associated face-name pairs. Each subject's results from before and after acute exercise are connected by a line. Solid line depicts subjects who fared better on the post-exercise test, dashed lines those who fared worse after acute physical exercise.

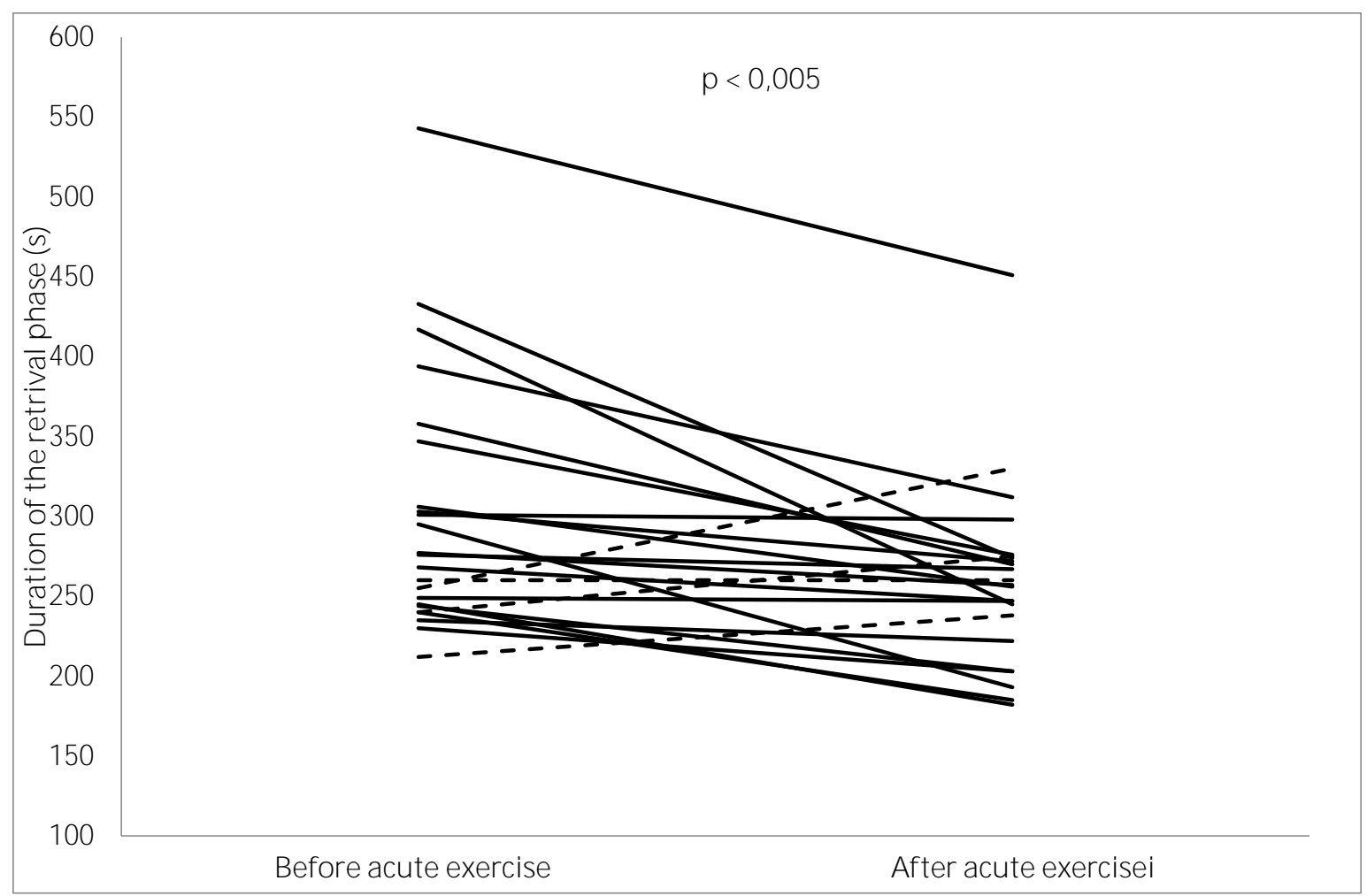

Fig.2. Individual scores in the face/name association test - duration of the retrieval phase. Each subject's results from before and after acute exercise are connected by a line. Solid line depicts subjects who fared better on the postexercise test, dashed lines those who fared worse after acute physical exercise. 


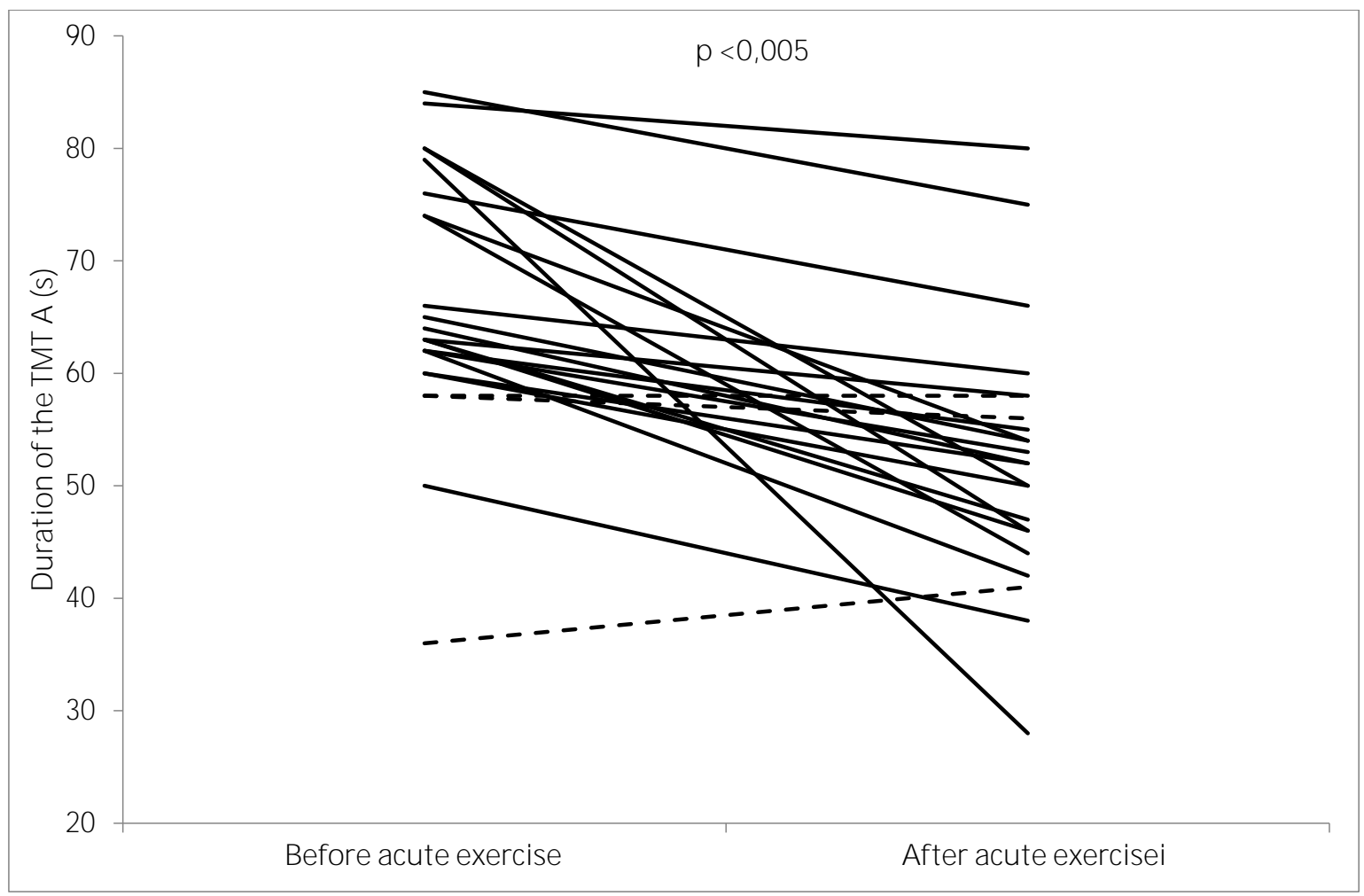

Fig.3. Individual scores in the Trial Making Test - duration of the TMT A phase. Each subject's results from before and after acute exercise are connected by a line. Solid line depicts subjects who fared better on the post-exercise test, dashed lines those who fared worse after physical exercise.

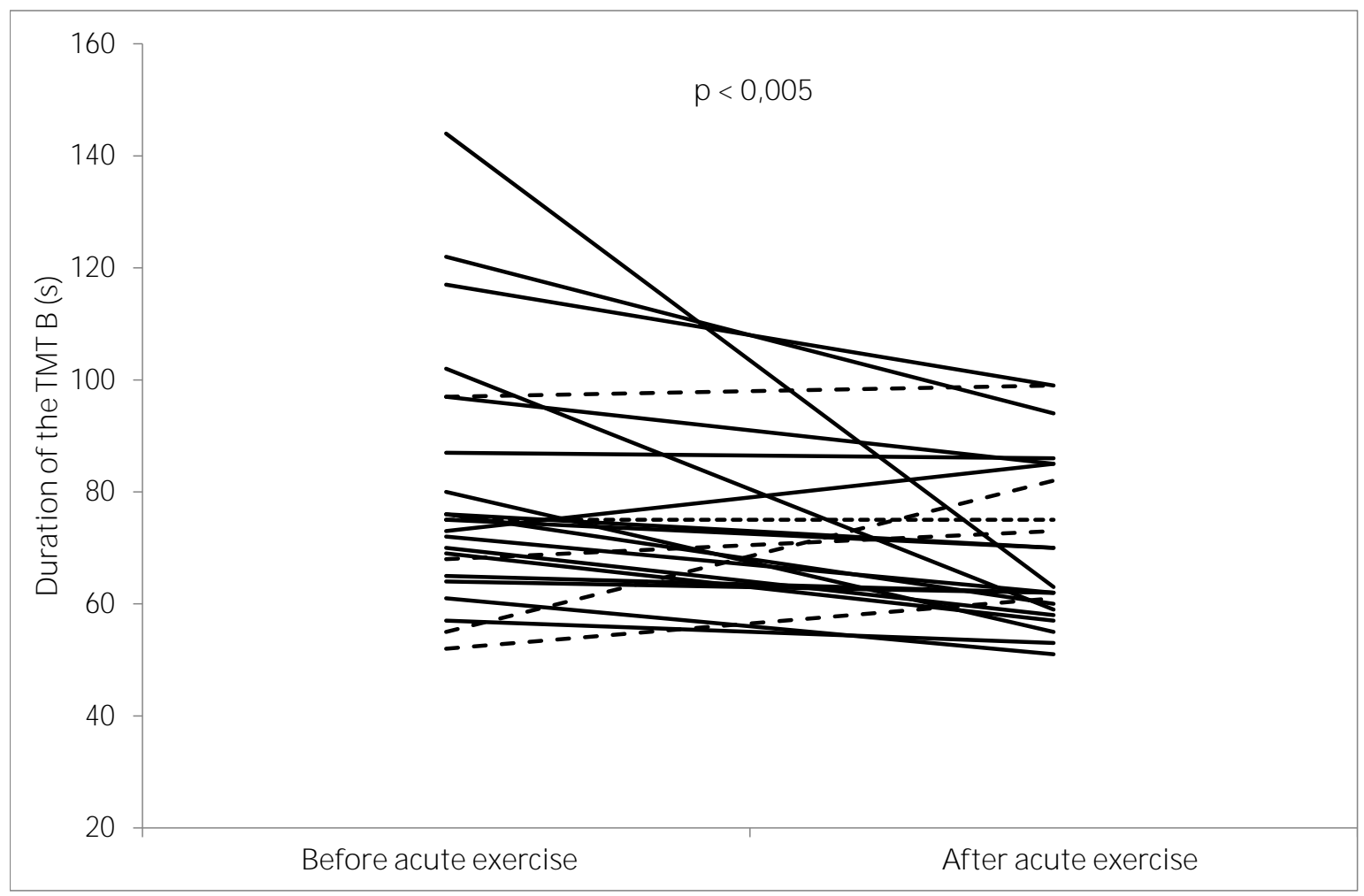

Fig.4. Individual scores in the Trial Making Test - duration of the TMT B phase. Each subject's results from before and after acute exercise are connected by a line. Solid line depicts subjects who fared better on the post-exercise test, dashed lines those who fared worse, dotted lines represents individuals with score unchanged after acute physical activity. 
result in the Stroop test was 199, $0 \pm 29,56 \%$ and 200 $\pm 27,02 \%$ in the before and after acute exercise results, respectively.

\section{Discussion}

The data presented in this report indicate that a single bout exercise can have significant influence on some cognitive function. 20-minutes of running improved short-term declarative memory expressed by Face/ Name Association Test and attention determined by Trial Making Test. There were no significant differences in the Stroop Test before and after a single bout exercise. Short-term declarative memory is closely associated with hippocampal activity while attention and cognitive flexibility depend on prefrontal cortex. Cognitive processes assessment by the Stroop test remain under control several discrete areas of cerebral cortex and are strongly associated with the activity of prefrontal and anterior cingulate cortical areas.

In contrast to studies of the impact of regular physical exercise on central nervous system, relatively limited number of publications describe influence of single bout exercise on cognitive function. Our findings are consistent with the results from other studies which demonstrated influence of acute exercise on cognitive function [17-21, 38]. However, the results obtained so far are difficult to interpret due to differences in duration, intensity, modality of exercise and the population assessed. Currently, the potential mechanism for the effect of single bout of physical activity on the cognitive function is unclear. Previous research suggests that acute exercise can impact cognitive processing by induced increase brain derived neurotrophic factor (BDNF), insulin-like growth factor (IGF-1) and increase peripheral levels of monoamines such as: dopamine, epinephrine and norepinephrine [3942]. 30 minutes running at moderate intensity can result in the increase of level BDNF, IGF-1, dopamine and maintain their elevated level up to 90 minutes after the end of exercise. BDNF stimulate growth of new neurons, neuronal differentiation and survival also enhances synaptic plasticity and may promote learning and memory. Studies have shown a positive association between acute exercise- induced peripheral BDNF levels and shortterm memory and motor skill memory [43-45]. Studies conducted by Winter et al. showed a significant increase in serum BDNF after anaerobic training. IGF-1 similar like BDNF regulate neurogenesis, neuronal survival and differentiation [39]. Single bout of exercise increase levels of dopamine and serotonin in hippocampus, prefrontal cortex and striatum [46-49]. This neurotransmitters may be a part of positive effect acute exercise has on cognitive functioning $[39,49,50]$.

The improvement of result in the Face/Name Association Test and Trail Making Test described in this paper may be a result of influence of 30 minutes running on neurotrophic factors and levels of monoamines. Although research conducted by our team doesn't indicate the mechanism of the observed change of cognitive abilities but they confirm earlier reports about the impact of acute exercise on cognitive function.

\section{Conclusion}

The data suggest that a single bout of exercise can influence on level some cognitive performance in young individuals. In our studied acute exercise improves cognitive function depending on hippocampus and prefrontal cortex However, more research is needed to understand the mechanisms of observed changes.

\section{Conflict of interests}

The authors have no conflict of interests to declare.

\section{References}

1. Autio J, Stenback V, Gagnon DD, Leppaluoto J, Herzig KH. (Neuro) Peptides, Physical Activity, and Cognition. Journal of Clinical Medicine. 2020;9(8). https://doi.org/10.3390/jcm 9082592

2. John A, Schollhorn WI. Acute Effects of Instructed and Self-Created Variable Rope Skipping on EEG Brain Activity and Heart Rate Variability. Frontiers in Behavioral Neuroscience, 2018;12. https://doi.org/10.3389/fnbeh.2018.00311

3. Szalewska D, Radkowski M, Demkow U, Winklewski PJ. Exercise Strategies to Counteract Brain Aging Effects. In: Pokorski M, editor. Clinical Research and Practice. Advances in Experimental Medicine and Biology. 10202017. p. 69-79.

4. Tivadar BK. Physical activity improves cognition: possible explanations. Biogerontology. 2017;18(4):477-483. https://doi.org/10.1007/s10522-017-9708-6

5. Kronenberg G, Bick-Sander A, Bunk E, Wolf C, Ehninger D, Kempermann G. Physical exercise prevents agerelated decline in prekursor cell activity in the mouse dentate gyrus. Neurobiol Aging, 2006; 27:1505-1513. https://doi.org/10.1016/j.neurobiolaging.2005.09.016
6. Gonzalez-Fernandez FT. Vigilance as key cognitive function in the relationship between acute physical exercise an cognition. Revista Iberoamericana De Ciencias De La Actividad Fisica Y El Deporte. 2019;8(1):39-53. https://doi.org/10.24310/riccafd.2019.v8i1.5762

7. Irwin $\mathrm{C}$, Campagnolo $\mathrm{N}$, Iudakhina $\mathrm{E}$, Cox GR, Desbrow B. Effects of acute exercise, dehydration and rehydration on cognitive function in well-trained athletes. Journal of Sports Sciences. 2018;36(3):247-255. https://doi.org/10.1080/02640414.2017.1298828

8. Lippi G, Mattiuzzi C, Sanchis-Gomar F. Updated overview on interplay between physical exercise, neurotrophins, and cognitive function in humans. Journal of Sport and Health Science. 2020;9(1):74-81. https://doi.org/10.1016/j.jshs.2019.07.012

9. Mile M, Tatai C, Fabian B, Csiki Z. Effects of physical activity on cognitive function in older adults. Orvosi Hetilap. 2020;161(5):163-168. https://doi.org/10.1556/650.2020.31643

10. Myers NL, Mexicano G, Aguilar KV. The Association Between Noncontact Injuries and the Acute-Chronic Workload Ratio in Elite-Level Athletes: ACritically Appraised Topic. Journal of Sport Rehabilitation. 2020;29(1):127-130. 
https://doi.org/10.1123/jsr.2018-0207

11. Grasdalsmoen M, Engdahl B, Fjeld MK, Steingrimsdottir OA, Nielsen CS, Eriksen HR, et al. Physical exercise and chronic pain in university students. Plos One. 2020;15(6). https://doi.org/10.1371/journal.pone.0235419

12.Zemkova E, Kovacikova Z, Zapletalova L. Is There a Relationship Between Workload and Occurrence of Back Pain andBack InjuriesinAthletes? FrontiersinPhysiology.2020;11. https://doi.org/10.3389/fphys.2020.00894

13.Jaffery A, Edwards MK, Loprinzi PD. The Effects of Acute Exercise on Cognitive Function: Solomon Experimental Design. Journal of Primary Prevention. 2018;39(1):37-46. https://doi.org/10.1007/s10935-017-0498-z

14. Voss MW, Weng TB, Narayana-Kumanan K, Cole RC, Wharff C, Reist L, et al. Acute Exercise Effects Predict Training Change in Cognition and Connectivity. Medicine and Science in Sports and Exercise. 2020;52(1):131-140. https://doi.org/10.1249/mss.0000000000002115

15.Labban JD, Etnier JL. The Effect of Acute Exercise on Encoding and Consolidation of Long-Term Memory. Journal of Sport \& Exercise Psychology. 2018;40(6):336-342. https://doi.org/10.1123/jsep.2018-0072

16. Wang CC, Chu CH, Ai JY, Yang KT, Chang YK. Effects of Acute Exercise Volume on Meta-Cognition in Middle-Aged and Older Adults. Journal of Sport \& Exercise Psychology. 2020;42:S110-S110.

17.Chmura J, Krysztofiak H, Ziemba AW, Nazar K, KaciubaUscilko H. Psychomotor performance during prolonged exercise above and below the blood lactate threshold. Eur J Appl Physiol Occup Physiol. 1998;77(1-2):77-80. https://doi.org/10.1007/s004210050303

18.Ludyga S, Gerber M, Brand S, Puhse U, Colledge F. Effects of Aerobic Exercise on Cognitive Performance Among Young Adults in a Higher Education Setting. Research Quarterly for Exercise and Sport. 2018;89(2):164-172. https://doi.org/10.1080/02701367.2018.1438575

19.Collardeau M, Brisswalter J, Audiffren M. Effects of a prolonged run on simple reaction time of well trained runners. Precept Mot Skills, 2001; 93 (3): 679-689. https://doi.org/10.2466/pms.2001.93.3.679

20.Wang XR, Zhu R, Zhou CL, Chen YF. Distinct Effects of Acute Aerobic Exercise on Declarative Memory and Procedural Memory Formation. Brain Sciences. 2020;10(10). https://doi.org/10.3390/brainsci10100691

21.Kamijo K. After effects of Cognitively Demanding Acute Aerobic Exercise on Working Memory. Medicine and Science in Sports and Exercise. 2018; 51(1): 153-159. https://doi.org/10.1249/MSS.0000000000001763

22.Loprinzi PD, Kane CJ. Exercise and cognitive function: a randomized controlled trial examining acute exercise and free-living physical activity and sedentary effects. Mayo Clin Pro. 2015;90(4):450-60. https://doi.org/10.1016/j.mayocp.2014.12.023

23.Nanda B, Balde J, Manjunatha S. The Acute Effects of a Single Bout of Moderate-intensity Aerobic Exercise on Cognitive Functions in Healthy Adult Males. J Clin Diag Res. 2013; 7(9): 1883-1885. https://doi.org/10.7860/JCDR/2013/5855.3341

24.Basso JC, Shang A, Elman M, Karmouta R, Suzuki WA. Acute exercise improves prefrontal cortex but not hippocampal function in healthy adults. Journal of the International Neuropsychological Society, 2015, 21: 791-8015. https://doi.org/10.1017/S135561771500106X

25.Dilley EK, Zou LY, Loprinzi PD. The effects of acute exercise intensity on episodic and false memory among young adult college students. Health Promotion Perspectives. 2019;9(2):143-149. https://doi.org/10.15171/hpp.2019.20

26.Green D, Loprinzi PD. Experimental Effects of Acute Exercise on Prospective Memory and False Memory. Psychological Reports. 2019;122(4):1313-1326. https://doi.org/10.1177/0033294118782466

27.Park S, Etnier JL. Beneficial Effects of Acute Exercise on Executive Function in Adolescents. Journal of Physical Activity \& Health. 2019;16(6):423-429. https://doi.org/10.1123/jpah.2018-0219

28.Ji LY, Li XL, Liu Y, Sun XW, Wang HF, Chen L, et al. Time-Dependent Effects of Acute Exercise on University Students' Cognitive Performance in Temperate and Cold Environments. Frontiers in Psychology. 2017;8. https://doi.org/10.3389/fpsyg.2017.01192

29.McHone A, Slutsky AB, Kurtz K, Arunachalam S, Labban JD, Etnier JL. The Effects of Acute Exercise Timing and Duration on Long-Term Memory. Journal of Sport \& Exercise Psychology. 2017;39:S287-S288.

30.Johnson L, Loprinzi PD. The effects of acute exercise on episodic memory function among young university students: moderation considerations by biological sex. Health Promotion Perspectives. 2019;9(2):99-104. https://doi.org/10.15171/hpp.2019.14

31. Statton MA, Encarnacian M, Celnik P, Bastian AJ. A single bout of moderate aerobic exercise improves motor skill acquisition. PLoS One. 2015; 10(10): 1-13. https://doi.org/10.1371/journal.pone.0141393

32.Złomańczuk P, Milczarek B, Dmitruk K et al. Improvement in the face/name association performance after three months of physical training in elderly women. J Physiol Pharmacol, 2006; 57(4):417-424.

33.Sperling RA, Bates JF, Cocchiarella AJ, Schacter DL, Rosen BR, Albert MS. Encoding novel face-name association; a functional MRI study. Hum Brain Mapp. 2001; 14: 129-139. https://doi.org/10.1002/hbm.1047

34.Golden CJ. A group version of Stroop Color and Ward test. Journal of Personality Assessment, 1975; 39:386-388. https://doi.org/10.1207/s15327752jpa3904_10

35.Pachana NA, Thompson WL, Marcopulos BA, YoashGantz R. California Older Adult Stroop Test (COAST): Development of a Stroop Test Adapted for Geriatric Populations. Clinical Gerontologist: The Journal of Aging and Mental Health, 2008; 27(3): 3-22. https://doi.org/10.1300/J018v27n03 02

36.Barch DM. Anterior Cingulate Cortex and Response Conflict: Effects of Response Modality and Processing Domain. Cerebral Cortex, 2001;11:837-48. https://doi.org/10.1093/cercor/11.9.837

37.Tombaugh TN. Trail Making Test A and B:Normative data stratified by age and education. Archives of Clinical Neuropsychology, 2004;19: 203-14. https://doi.org/10.1016/S0887-6177(03)00039-8

38. Harveson AT, Hannon JC, Brusseau TA, Podlog L, Papadopoulos C, Hall MS, et al. Acute Exercise and Academic AchievementinMiddleSchoolStudents. InternationalJournal of Environmental Research and Public Health. 2019;16(19). https://doi.org/10.3390/ijerph16193527

39. Winter B, Breitenstein C, Mooren FC, Voelker K, Fobker M, Lechtermann A, et al. High impact running improves learning. Neurobiology of Learning and Memory, 2007;87:597-609. https://doi.org/10.1016/j.nlm.2006.11.003

40.Clement KA, Carr S, Johnson L, Carter A, Dosch BR, Kaufman J, et al. Reading, writing, and ... running? 
Assessing active space in libraries. Performance Measurement and Metrics. 2018;19(3):166-175. https://doi.org/10.1108/pmm-03-2018-0011

41.Skriver K, Roig M, Lundbye-Jensen J, Pingel J, Helge JW, Kiens B, et al. Acute exercise improves motor memory: Exploring potential biomarkers. Neurobiology of Learning and Memory, 2014;116:46-58. https://doi.org/10.1016/j.nlm.2014.08.004

42.Musso NR, Gianrossi R, Pende A, Vergassola C, Lotti G. Plasma dopamine response to sympathetic activation in man: A biphasic pattern. Life Sciences, 1990;47:619-26. https://doi.org/10.1016/0024-3205(90)90573-A

43.Lee JLC, Everitt BJ, Thomas KL. Independent Cellular Processes for Hippocampal Memory Consolidation and Reconsolidation. Science, 2004; 304(5672): 839-43. https://doi.org/10.1126/science.1095760

44. Voss MW, Soto C, Yoo S, Sodoma M, Vivar C, van Praag H. Exercise and Hippocampal Memory Systems. Trends in Cognitive Sciences. 2019;23(4):318-333. https://doi.org/10.1016/j.tics.2019.01.006

45.Skriver K, Roig M, Lundbye-Jensen J, Pingel J, Helge JW, Kiens B, Nielsen JB. Acute exercise improves motor memory: exploring potential biomarkers. Neurobiol Learn Mem. 2014;116: 46-58. https://doi.org/10.1016/j.nlm.2014.08.004

46. Meeusen R, Demeirleir K. Exercise and brain neurotransmission. Sports Medicine, 1995; 20(3):160-188. https://doi.org/10.2165/00007256-199520030-00004

47.Meeusen R, Piacentini MF, De Meirleir K. Brain microdialysis in exercise research. Sports Med. 2001; 31(14): 965-983. https://doi.org/10.2165/00007256-200131140-00002

48. Waters A, Zou LY, Jung MJ, Yu Q, Lin JY, Liu SJ, et al. Acute Exercise and Sustained Attention on Memory Function. American Journal of Health Behavior. 2020;44(3):326-332. https://doi.org/10.5993/ajhb.44.3.5

49.Ding Q, Vaynman S, Akhavan M, Ying Z, GomezPinilla F. Insulin-like growth factor I interfaces with brain-derived neurotrophic factor-mediated synaptic plasticity to modulate aspects of exercise-induced cognitive function. Neuroscience, 2006;140:823-33. https://doi.org/10.1016/j.neuroscience.2006.02.084

50.Loprinzi PD, Ponce P, Frith E. Hypothesized mechanisms through which acute exercise influences episodic memory. Physiology International. 2018;105(4):285-297. https://doi.org/10.1556/2060.105.2018.4.28

\section{Information about the authors:}

Blanka Dwojaczny; (Corresponding author); https://orcid.org/0000-0002-2253-1502; blanka.dwojaczny@cm.umk.pl; Department of Human Physiology, Collegium Medicum im. L.Rydygiera Bydgoszcz, Nicolaus Copernicus University in Toruń; Toruń, Poland.;

Sergii lermakov; Doctor of Sciences in Pedagogy, Professor; http://orcid.org/0000-0002-5039-4517; sportart@gmail.com; Department of Sport, Gdansk University of Physical Education and Sport; Gdansk, Poland.

Tatiana Yermakova; Doctor of Sciences in Pedagogy, Professor; https://orcid.org/0000-0002-3081-0229; yermakova2015@ gmail.com; Department of Pedagogy, Kharkov State Academy of Design and Arts; Kharkov, Ukraine.

Mirosława Cieślicka; http://orcid.org/0000-0002-0407-2592; m.cieslicka@cm.umk.pl; Department of Human Physiology, Collegium Medicum im. L.Rydygiera Bydgoszcz, Nicolaus Copernicus University in Toruń; Toruń, Poland.

Cite this article as:

Dwojaczny B, lermakov S, Yermakova T, Cieślicka M. The effect of acute exercise on cognition. Physical Education of Students, 2020;24(6):325-331.

https://doi.org/10.15561/20755279.2020.0604

This is an Open Access article distributed under the terms of the Creative Commons Attribution License, which permits unrestricted use, distribution, and reproduction in any medium, provided the original work is properly cited http://creativecommons.org/licenses/by/4.0/deed.en

Received: 30.10 .2020

Accepted: 02.12.2020; Published: 30.12 .2020 